\title{
Melatonin Effectively Preserves Cognitive Function in Club Drug Intoxicated Rats
}

\author{
Huang YL ${ }^{1}$, Liao WC ${ }^{1}$, Chen $\mathrm{LY}^{1}$, Mai FD ${ }^{2}$ and Chang $\mathrm{HM}^{* 3}$ \\ ${ }^{1}$ Department of Anatomy, Faculty of Medicine, Chung Shan Medical University, Taichung, Taiwan \\ ${ }^{2}$ Department of Biochemistry and Molecular Cell Biology, Taipei Medical University, Taipei, Taiwan \\ ${ }^{3}$ Department of Anatomy and Cell Biology, Taipei Medical University, Taipei, Taiwan
}

*Corresponding author: Chang HM, Department of Anatomy and Cell Biology, Taipei Medical University, Wu Hsing St., Taipei, Taiwan 11031, Tel: +886-2-2736-1661, E-mail: taiwanzoo@gmail.com

Citation: Huang YL, Liao WC, Chen LY, Mai FD, Chang HM (2015) Melatonin Effectively Preserves Cognitive Function in Club Drug Intoxicated Rats. J Cell Biol Histol 1(1): 102. doi: 10.15744/2638-082X.1.102

Received Date: April 22, 2015 Accepted Date: August 24, 2015 Published Date: August 26, 2015

\begin{abstract}
Background: Excessive exposure to club drug gamma-hydroxybutyric acid (GHB) would cause cognitive dysfunction in which impaired $\mathrm{Ca}^{2+}$-mediated neuroplasticity in hippocampus may play an essential role in the pathogenesis of this deficiency. Considering melatonin is positive for neuroplastic regulation, the present study aims to determine whether melatonin would exert a neuro-protective effect on cognitive function following GHB.

Materials and Methods: Adolescent rats subjected to ten days of GHB (500 mg/kg) and received $10 \mathrm{or} 100 \mathrm{mg} / \mathrm{kg}$ of melatonin were processed for time-of-flight secondary ion mass spectrometry (TOF-SIMS), quantitative immunohistochemistry, biochemical and radiographic assay, together with Morris water maze to analyze the ionic, neurochemical, bio-energetic, and behavioral effects of melatonin on GHB-induced cognitive dysfunction, respectively.

Results: In GHB intoxicated rats, decreased $\mathrm{Ca}^{2+}$ imaging and depressed $\mathrm{Ca}^{2+}$-mediated signaling were detected in hippocampal neurons. The diminished expression of these signaling molecules corresponded well with intense oxidative stress, reduced bio-energetics, and poor performances in cognitive activities. However, in rats received different doses of melatonin during GHB intoxication, all above parameters were gradually returned to nearly normal levels in which the maximal change was detected in animals given the dose of 100 $\mathrm{mg} / \mathrm{kg}$.

Conclusion: As melatonin effectively preserves cognitive function by saving the hippocampal bio-energetics through maintaining the $\mathrm{Ca}^{2+}$-mediated neuroplasticity, therapeutic use of melatonin may thus serve as a promising strategy to improve or counteract cognitive dysfunction induced by drug addiction prevailing in our society nowadays.
\end{abstract}

Keywords: Gamma-Hydroxybutyric Acid; Neuroplasticity; Bio-Energetics; Cognitive Function; Quantitative Ionic Imaging Analysis

\section{Introduction}

Gamma-hydroxybutyric acid (GHB) is a new club drug with highly addictive potential among adolescents [1-3]. Due to its significant euphorigenic effects, excessive exposure to GHB would cause cognitive dysfunction, cardiovascular disorder, metabolic deficiency and even death [4-8]. However, despite the abuse and prevalence of GHB is an on-going public health problem in our society, the mechanism(s) of GHB-induced cognitive dysfunction is still not well known and remains an under-researched topic [9]. Within the past few years, the impaired $\mathrm{Ca}^{2+}$-mediated neuroplasticity in the hippocampus has been suggested to be positively correlated with the formation of cognitive deficiency [10-12]. Through extensively interrupting the Ca ${ }^{2+}$-mediated signaling, hippocampal neurons would suffer from bio-energetic dysfunction, which subsequently contributes to the impairment of synaptic function and cognitive activity [10].

Long-term potentiation (LTP) is a molecular phenomenon characterized by pronounced synaptic transmission that plays an important role in memory formation and cognitive activity [13-15]. The $N$-methyl-D-aspartate (NMDA) receptor-mediated Ca ${ }^{2+}$ influx into post-synaptic neurons is the critical event leading to the induction of LTP [16,17]. Extensive influx of Ca ${ }^{2+}$ would trigger nitric oxide (NO) production, which strengthens the synaptic transmission through modulating the gene transcription factor activity $[18,19]$. Repeated GHB exposure has been reported to depress the cortical NMDA receptor expression [20]. Pharmacological reports also demonstrated that GHB overdose would cause oxidative stress that consequently leads to learning and memory deficiency $[21,22]$. As depressed LTP and oxidative stress play essential roles in impairing cognitive function, exploring the bio-energetics as well as the molecular machinery engaged in neuroplastic regulation would shed an important light for clinical design of therapeutic agent to decrease or counteract the GHB-related cognitive deficiency. 
Melatonin, the chief secretory product of pineal gland, is a potential regulator of memory formation, long-term potentiation, synaptic transmission, as well as neuronal plasticity [23-25]. During the past few years, the functional role of melatonin in improving cognitive function under a variety of experimental insults has been greatly reported [26-30]. It is indicated that the neuroprotective effects of melatonin on cognitive function was mediated by effectively reducing the hippocampal oxidative stress and successfully enhancing the signaling molecules participated in bio-energetic activity [31,32]. Based on this viewpoint, application of melatonin in the treatment of cognitive dysfunction induced by GHB may therefore be worthy of trial to preserve the well-maintenance of learning and higher conscious activity.

However, although the functional role of $\mathrm{Ca}^{2+}$-mediated signaling in potentiating the hippocampal neuroplasticity has been well documented [10], the potential changes of in vivo $\mathrm{Ca}^{2+}$, together with the molecular machinery involved in bio-energetic regulation following GHB has never been reported. Moreover, whether GHB-induced cognitive dysfunction would effectively be restored by melatonin administration still remains to be further explored. In order to answer these questions, the present study is firstly aimed to determine the neuroplastic and bio-energetic changes induced by GHB through molecular imaging, spectrometric, biochemical, neurochemical, as well as behavioral approaches. Secondly, as to investigate whether melatonin would exert a neuroprotective effect on cognitive function, two different doses of melatonin (with a ten-fold difference) were administrated to adolescent rats subjected to GHB.

\section{Materials and Methods}

\section{Treatment of Experimental Animals}

Adolescent male Wistar rats obtained from the Laboratory Animal Center of the Chung Shan Medical University were used in this study. The experimental animals were divided into five groups equally. Rats in the first group (Group I, n = 10) were intraperitoneally (i.p.) injected with GHB $(500 \mathrm{mg} / \mathrm{kg}$ ) for ten successive days. Rats in the second to fourth groups were daily injected with $500 \mathrm{mg} / \mathrm{kg}$ GHB combined with Ringer's solution (Group II) or melatonin at the doses of $10 \mathrm{mg} / \mathrm{kg}$ (Group III) and $100 \mathrm{mg} / \mathrm{kg}$ (Group IV), respectively, between 10:00 and 10:30 h. Rats in the last group (Group V) did not receive any treatment and kept as normal untreated control. GHB (courtesy of the Food and Drug Administration, Ministry of Health and Welfare, Taipei, Taiwan) was prepared in physiological saline. Melatonin (Sigma, St. Louis, MO, USA) was first dissolved in absolute alcohol and then diluted in Ringer's solution with the final ethanol concentration less than $1 \%$. During the experimental period, all rats were exposed to the light-dark cycle of 12:12 (light on 07:00 - 19:00 h) at a constant temperature of $25 \pm 1^{\circ} \mathrm{C}$. The animals were allowed to food and water ad libitum. In the care and handling of all experimental animals, the Guide for the Care and Use of Laboratory Animals (1985) as stated in the United States NIH guidelines (NIH publication No. 86-23) were followed. All the experimental procedures were further approved by the Committee on Care and Use of Laboratory Animals of the Chung Shan Medical University (IACUC Approval No 9426).

\section{Morris Water Maze Learning Test}

After ten days of GHB or melatonin consecutive administration, all rats were undergone the Morris water maze test to examine the performance of spatial learning and memory [28]. Rats placed in the water maze were trained to find the hidden platform according to the spatial cues in the experimental room. Place learning was assessed for eight training trials on the last day of the experiment. The maze performance was recorded by a video camera suspended above the maze and interfaced with a video tracking system (San Diego Instruments, CA, USA).

A probe trial was given $12 \mathrm{~h}$ after training, and the percent time spent in the target quadrant was used to indicate the degree of memory consolidation that has taken place after learning [28].

To test the possible deficits in motoric function after GHB, the rats were tested with a visible platform. The swimming speed to reach the platform was also recorded for each trial.

\section{Perfusion and Tissue Preparation}

For TOF-SIMS and quantitative morphological analysis, half amounts of rats from all experimental groups were deeply anesthetized with $7 \%$ chloral hydrate and perfused transcardially with saline followed by $4 \%$ paraformaldehyde in $0.1 \mathrm{M}$ phosphate buffer (PB). After perfusion, the hippocampus was removed and cut into 30- $\mu \mathrm{m}$-thick sections with a cryostat (CM3050S, Leica Microsystems, Wetzlar, Germany) on the following day. The collected sections were alternatively placed into three wells of a culture plate. Sections collected in the first well were processed for TOF-SIMS analysis, and those in the second and third wells were processed for NMDA receptor subunit 1 (NMDAR1) and phosphorylated cAMP-response element binding protein (p-CREB) immunohistochemistry, respectively.

\section{TOF-SIMS Analysis}

TOF-SIMS analysis was carried out on a TOF-SIMS IV instrument (ION-TOF GmbH, Munster, Germany) as described in our previous studies [11,33]. Gallium $\left(\mathrm{Ga}^{+}\right)$ion gun operated at $25 \mathrm{kV}$ was used as the primary ion source. Positive secondary ions flying through a reflection mass spectrometer were detected with a micro-channel plate. The paraformaldehyde and a set of standard peaks [like $m / z 15\left(\mathrm{CH}_{3}^{+}\right), 27\left(\mathrm{C}_{2} \mathrm{H}_{3}^{+}\right)$, and $41\left(\mathrm{C}_{3} \mathrm{H}_{5}^{+}\right)$] were used as mass calibration to ameliorate the potential matrix effect for ion spectrums [33]. The ions related to $m / z 23, \mathrm{~m} / z$ 39.09, and $m / z 40.08$ was used to identify $\mathrm{Na}^{+}$, $\mathrm{K}^{+}$, and $\mathrm{Ca}^{2+}$, respectively. 


\section{Quantitative NMDAR1 and p-CREB Immunohistochemistry}

For NMDAR1 and p-CREB immunohistochemistry, sections placed in blocking medium were incubated with primary antibody against NMDAR1 (1:75) (Chemi-Con AB1516, Temecula, CA, USA) and p-CREB (1:100) (Cell Signaling 9198, Danvers, MA, USA) for $48 \mathrm{~h}$ at $4{ }^{\circ} \mathrm{C}$. Following that, sections were incubated with a biotinylated secondary antibody (1:200) (Vector Laboratories, Burlingame, CA, USA) at room temperature for $2 \mathrm{~h}$, followed by standard avidin-biotin complex procedure with diaminobenzidine as a substrate of peroxidase.

\section{Measurement of Hippocampal Lipid Peroxidation}

The hippocampus excised from another half amounts of rats were homogenized and centrifuged firstly. The supernatants were then taken for detecting MDA by measurement of fluorescence product formed from the reaction of MDA with thiobarbituric acid. The results were determined spectrophotometrically at $532 \mathrm{~nm}$ using tetraethoxypropane as a standard, and expressed as nmol/ $\mathrm{mg}[34]$.

\section{Hippocampal nNOS Activity Assay}

Total nNOS activity was determined by measuring the conversion of L- $\left[{ }^{14} \mathrm{C}\right]$-arginine to L- $\left[{ }^{14} \mathrm{C}\right]$-citrulline [11]. Hippocampal extract $(50 \mu \mathrm{L})$ incubated in reaction mixture were applied to Dowex AG50W-X8 column to remove L-[14C]-arginine. The $\mathrm{L}-\left[{ }^{14} \mathrm{C}\right]$-citrulline was quantified by liquid scintillation spectrophotometry (Beckman LS 3801). 1 U of total nNOS activity was defined as picomoles of $\mathrm{L}-\left[{ }^{14} \mathrm{C}\right]$-citrulline produced per minute per microgram protein. The nNOS activity was expressed as units per milligram of hippocampal protein (U/mg Protein).

\section{Hippocampal $\mathrm{Na}^{+} / \mathrm{K}^{+}$ATPase Activity Assay}

For hippocampal $\mathrm{Na}^{+} / \mathrm{K}^{+}$ATPase activity assay, tissue samples were homogenized and centrifuged firstly. The supernatants were then used for $\mathrm{Na}^{+} / \mathrm{K}^{+}$ATPase activity assay by reacting with incubation medium at $37{ }^{\circ} \mathrm{C}$. After that, the reaction was initiated by addition of ATP to a final concentration of $3 \mathrm{mM}$. Controls were carried out under the same conditions with the addition of 1 $\mathrm{mM}$ of ouabain. Specific activity of $\mathrm{Na}^{+} / \mathrm{K}^{+}$ATPase was expressed as nmol of inorganic phosphate (Pi) released per min per mg of protein.

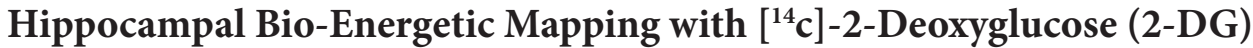

To evaluate the hippocampal bio-energetic activity, rats from each experimental groups were intra peritoneally injected with 2-DG $(100 \mu \mathrm{Ci} / \mathrm{kg}$; specific activity $=390 \mathrm{mCi} / \mathrm{mmol}$; VWR, Radnor, PA, USA) after ten days of GHB exposure with or without melatonin treatment. After $45 \mathrm{~min}$, animals were perfused and the hippocampal sections were apposed to high-resolution X-ray film (Structurix, Agfa, Belgium) with $\left[{ }^{14} \mathrm{C}\right]$ microscales (Amersham, Piscataway, NJ, USA). Sections were exposed at $-80{ }^{\circ} \mathrm{C}$ for ten days. After that, films were developed, fixed, and then digitized for the uptake of 2-DG followed the methods described previously [35].

\section{Quantitative Study and Image Analysis}

The general approach for quantitative image analysis was similar to our previous studies [28,36]. A computer based image analysis system along with the Image-Pro Plus software (Media Cybernetics, Silver Spring, MD, USA) was used to quantify the staining intensity. The hippocampal neurons reacted for NMDAR1 and p-CREB were densitometrically measured, and all readings were averaged to obtain the total OD (TOD). Background staining (BOD) was measured on vascular spaces adjoining the hippocampus. True OD was expressed by subtracting the BOD from TOD, so that each measurement was made in an unbiased way. All images were captured on the same day by the same experimenter to maintain the uniform settings.

\section{Statistical Analysis}

For TOF-SIMS analysis, spectral intensity detected from each section were normalized to ion intensity of paraformaldehyde (serve as base line $=100 \%$ ) and expressed as percentage above the base line [33]. Statistical analysis was performed with SPSS for Windows, version 17.0. Comparisons of the data acquired from different experimental groups were subjected to KolmogorovSmirnov test for analyzing the pattern of normality. Those qualified were subsequently processed for one-way ANOVA followed by Bonferroni post hoc test [37]. Statistical difference was considered significant if $P<0.05$.

\section{Results}

In normal untreated rats, strong $\mathrm{Ca}^{2+}$ intensities with significant intracellular localization were detected in hippocampal neurons by the use of ionic imaging and TOF-SIMS analysis (Figure 1A,E). The enhanced hippocampal Ca ${ }^{2+}$ expression corresponded well with the quantitative immunohistochemical and biochemical studies in which an intense NMDA receptor expression (Figure 2A,E), high level of nNOS activity (Figure 3), and enhanced CREB phosphorylation (p-CREB) (Figure 4A,E) were all clearly detected in hippocampus of normal untreated animals. The normal activation of these molecular elements positively correlated with the intact bio-energetics in which lower level of oxidative stress (Figure 5), enhanced $\mathrm{Na}^{+} / \mathrm{K}^{+}$ATPase activity (Figure 6A,E,I), 
and strong radioactive signals of 2-DG (Figure 7A,E) were markedly demonstrated in hippocampal neurons of normal untreated ones. Behavioral data coincided well with above findings in which animals expressed higher bio-energetics exhibited good performances in Morris water maze test of spatial learning (Figure 8A) and spatial memory (Figure 8B).
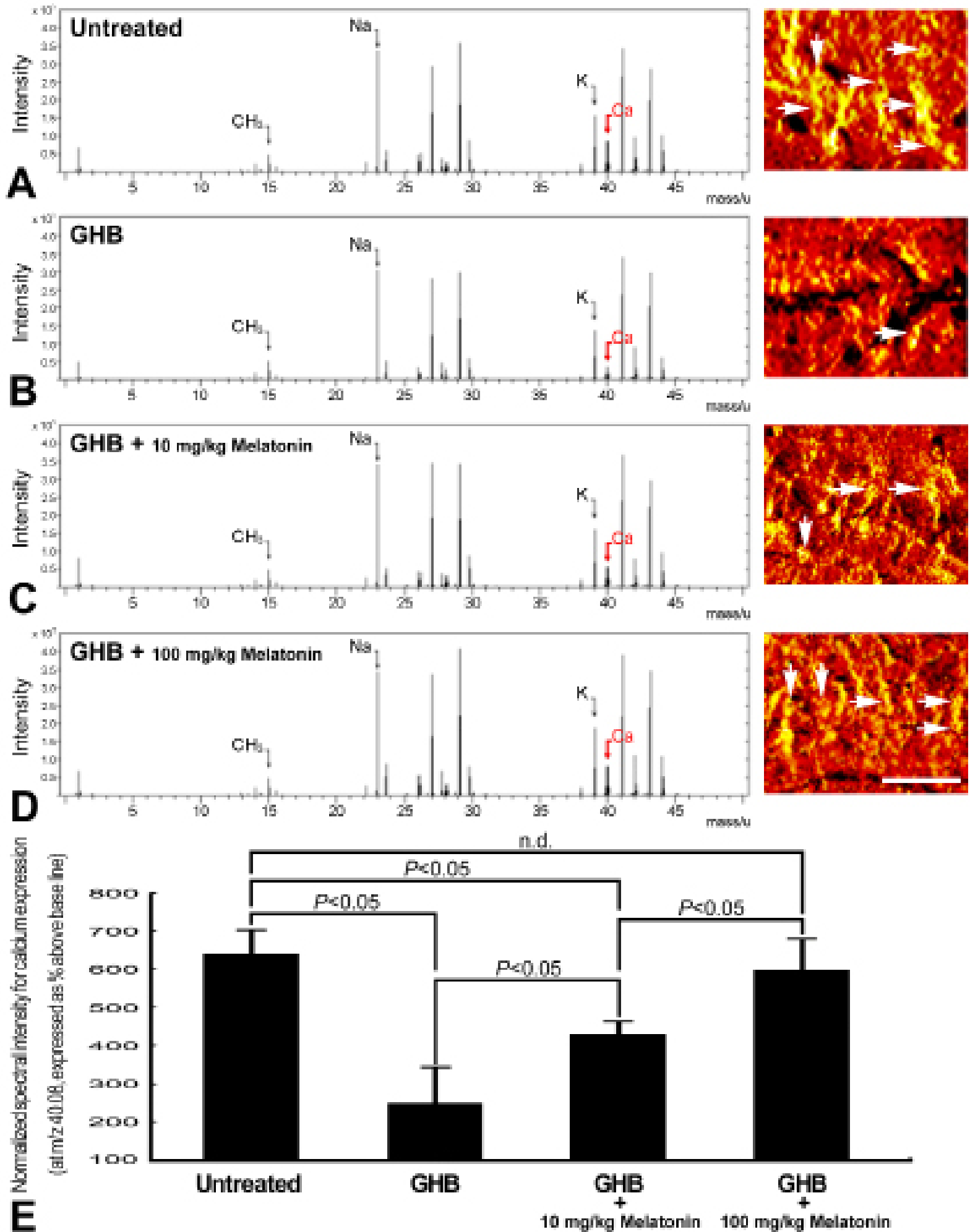

Figure 1: TOF-SIMS positive spectra/ionic imaging (A-D) and histogram (E) showing the hippocampal Ca ${ }^{2+}$ expression in the normal untreated (A), $\gamma$-hydroxybutyric acid (GHB) intoxicated (B), and GHB intoxication with $10 \mathrm{mg} / \mathrm{kg}(\mathrm{C})$ and $100 \mathrm{mg} / \mathrm{kg}$ (D) melatonin treated rats. The ionic imaging of $\mathrm{Ca}^{2+}$ signaling is expressed by a color scale in which bright colors represent high levels of Ca ${ }^{2+}$. Note that in normal untreated rats, strong calcium intensity with significant intracellular localization was detected in pyramidal neurons of the hippocampus [arrows in (A)]. Following GHB intoxication, the hippocampal $\mathrm{Ca}^{2+}$ expression was drastically decreased in both terms of ionic intensity and intracellular distribution (B). However, in animals intoxicated by GHB and received different doses of melatonin, the hippocampal $\mathrm{Ca}^{2+}$ expression was significantly increased in which the maximal increment was observed in animals receiving higher dose of melatonin $(100 \mathrm{mg} / \mathrm{kg})(\mathrm{D})$. Data from normalized spectral intensity analysis corresponded well with imaging findings in which melatonin effectively increase the hippocampal Ca ${ }^{2+}$ intensity (E). Also note that the spectral intensity for normalization (i.e. $\mathrm{CH} 3$ at $\mathrm{m} / z$ 15) were similar among numerous experimental groups, suggested that the intensity change of Ca ${ }^{2+}$ detected was a reliable and distinct effect. Scale bar $=100 \mu \mathrm{m}$. (A-D). 

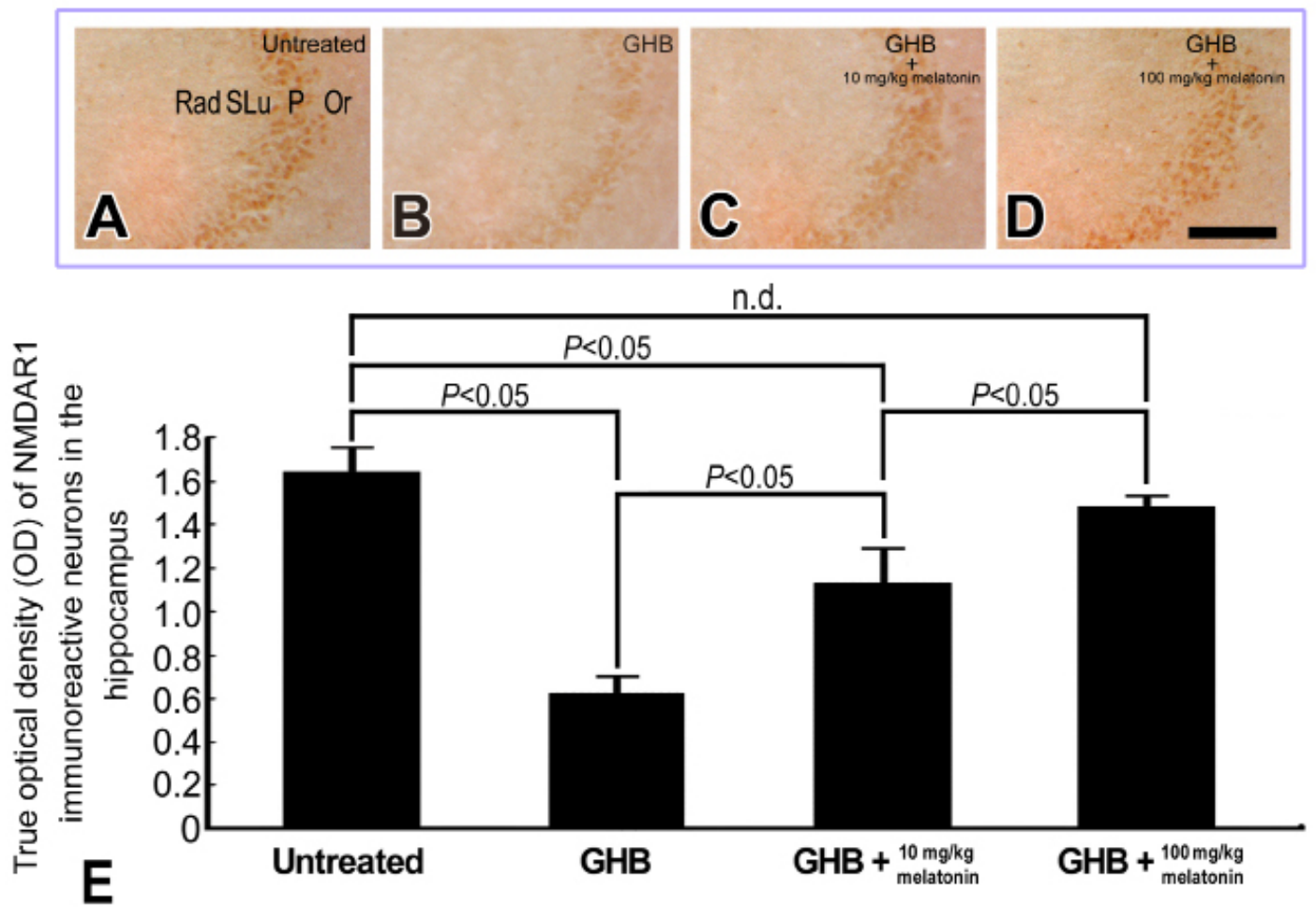

Figure 2: Light photomicrographs (A-D) and histogram (E) showing the hippocampal N-methy- D-aspartate receptor subunit 1 (NMDAR1) immunoreactivity in the normal untreated (A), $\gamma$-hydroxybutyric acid (GHB) intoxicated (B), and GHB intoxication with $10 \mathrm{mg} / \mathrm{kg}$ (C) and $100 \mathrm{mg} / \mathrm{kg}$ (D) melatonin treated rats. Note that in normal untreated rats, numerous NMDAR1 immunoreactive neurons with strong staining intensities were observed in hippocampal pyramidal cell layers (A). Following GHB intoxication, the NMDAR1 immunoreactivity was drastically decreased (B). However, in animals intoxicated by GHB and received different doses of melatonin, the hippocampal NMDAR1 immunoreactivity was gradually returned to nearly normal levels in which the highest expression was detected in animals received melatonin at $100 \mathrm{mg} / \mathrm{kg}$ (D). Densitometric analysis supported the neurochemical findings in which melatonin effectively preserved the optical density of hippocampal NMDAR1 immunoreactivity (E). Rad: stratum radiatum; SLu: stratum lucidum; P: pyramidal cell layer; Or: stratum oriens. Scale bar $=200 \mu \mathrm{m}$. (A-D).

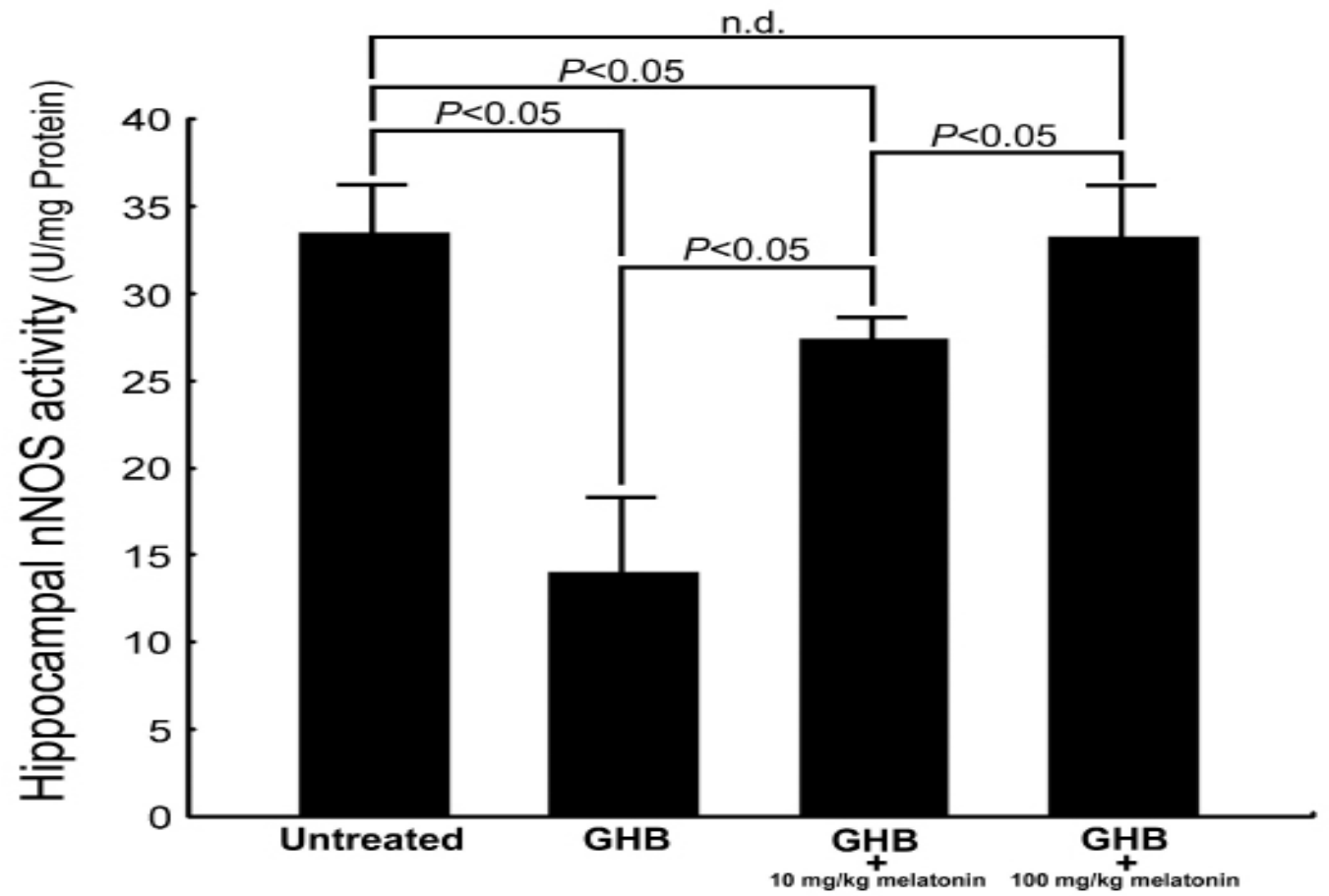

Figure 3: Histogram showing the neuronal nitric oxide synthase (nNOS) activity in the hippocampus of normal untreated, $\gamma$-hydroxybutyric acid (GHB) intoxicated, and GHB intoxication with $10 \mathrm{mg} / \mathrm{kg}$ and $100 \mathrm{mg} / \mathrm{kg}$ melatonin treated rats. Note that GHB exposure remarkably decreases the hippocampal nNOS activity. However, in animals exposed to GHB and received different doses of melatonin, the hippocampal nNOS activity was significantly increased with the maximal change observed in animals received melatonin at the dose of $100 \mathrm{mg} / \mathrm{kg}$. 


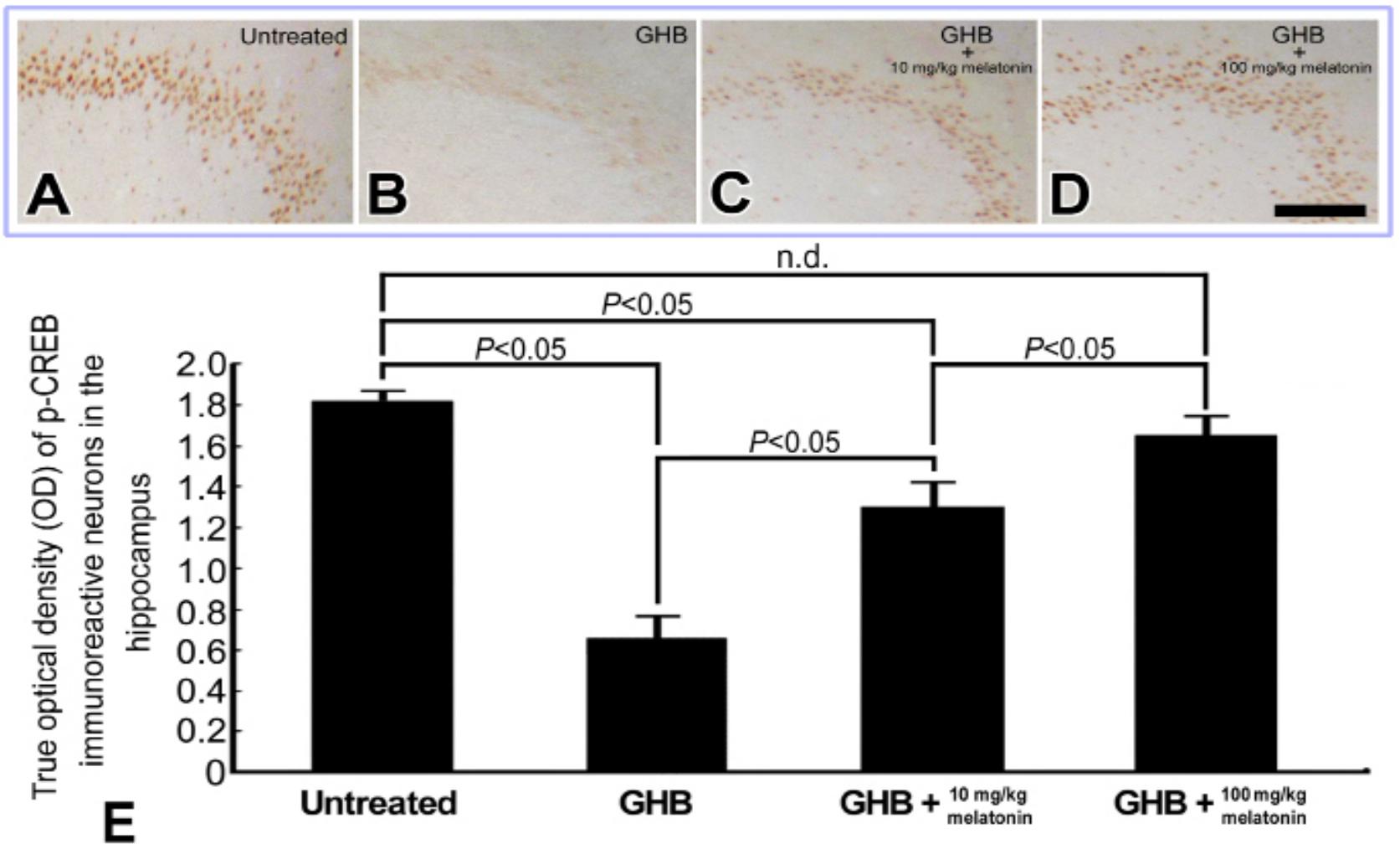

Figure 4: Light photomicrographs (A-D) and histogram (E) showing the phosphorylated cAMP- responsive element binding protein (p-CREB) immunoreactivity in the hippocampus of normal untreated (A), $\gamma$-hydroxybutyric acid (GHB) intoxicated (B), and GHB intoxication with $10 \mathrm{mg} / \mathrm{kg}(\mathrm{C})$ and $100 \mathrm{mg} / \mathrm{kg}$ (D) melatonin treated rats. Note that in normal untreated rats, numerous neurons with strong p-CREB staining intensities were observed in the CA1 region of hippocampus (A). Following GHB intoxication, the immuno-expression of hippocampal p-CREB was drastically decreased (B). However, in animals intoxicated by GHB and received different doses of melatonin, the hippocampal p-CREB immunoreactivity were significantly increased in which the highest expression was detected in animals received $100 \mathrm{mg} / \mathrm{kg}$ of melatonin (D). Computerized image analysis corresponded well with immunohistochemical findings in which melatonin successfully preserved the hippocampal p-CREB immunoreactivity (E). Scale bar $=200 \mu \mathrm{m}$. (A-D).

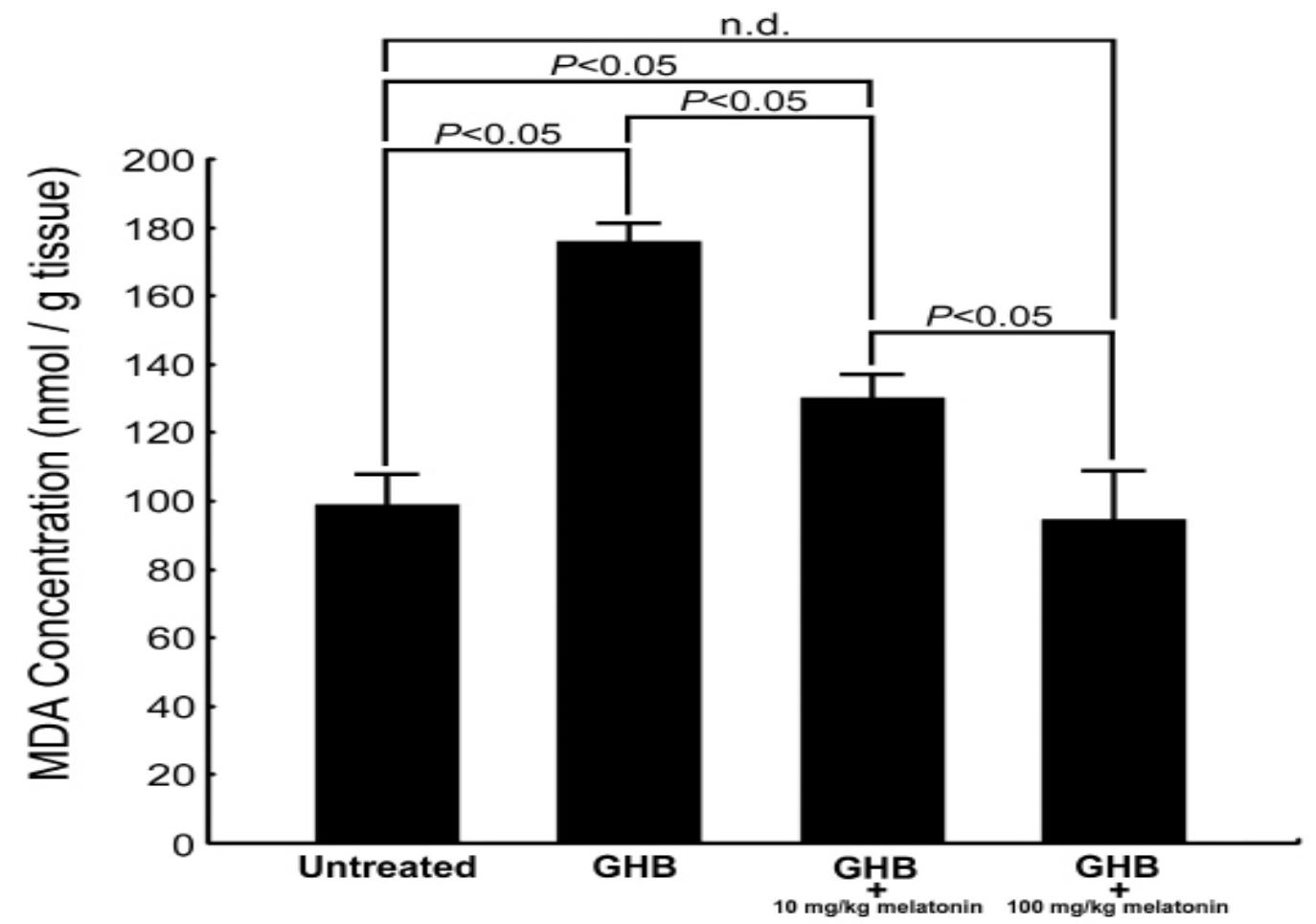

Figure 5: Histogram showing the extent of oxidative stress [as demonstrated by malondialdehyde (MDA) level] in the hippocampus of normal untreated, $\gamma$-hydroxybutyric acid (GHB) intoxicated, and GHB intoxication with $10 \mathrm{mg} / \mathrm{kg}$ and $100 \mathrm{mg} / \mathrm{kg}$ melatonin treated rats. Note that intense oxidative stress was detected in the hippocampus of GHB intoxicated rats. However, in animals intoxicated by GHB and received different doses of melatonin, the hippocampal oxidative stress was significantly decreased in which the maximal reduction was observed in animals received melatonin at the dose of $100 \mathrm{mg} / \mathrm{kg}$. 

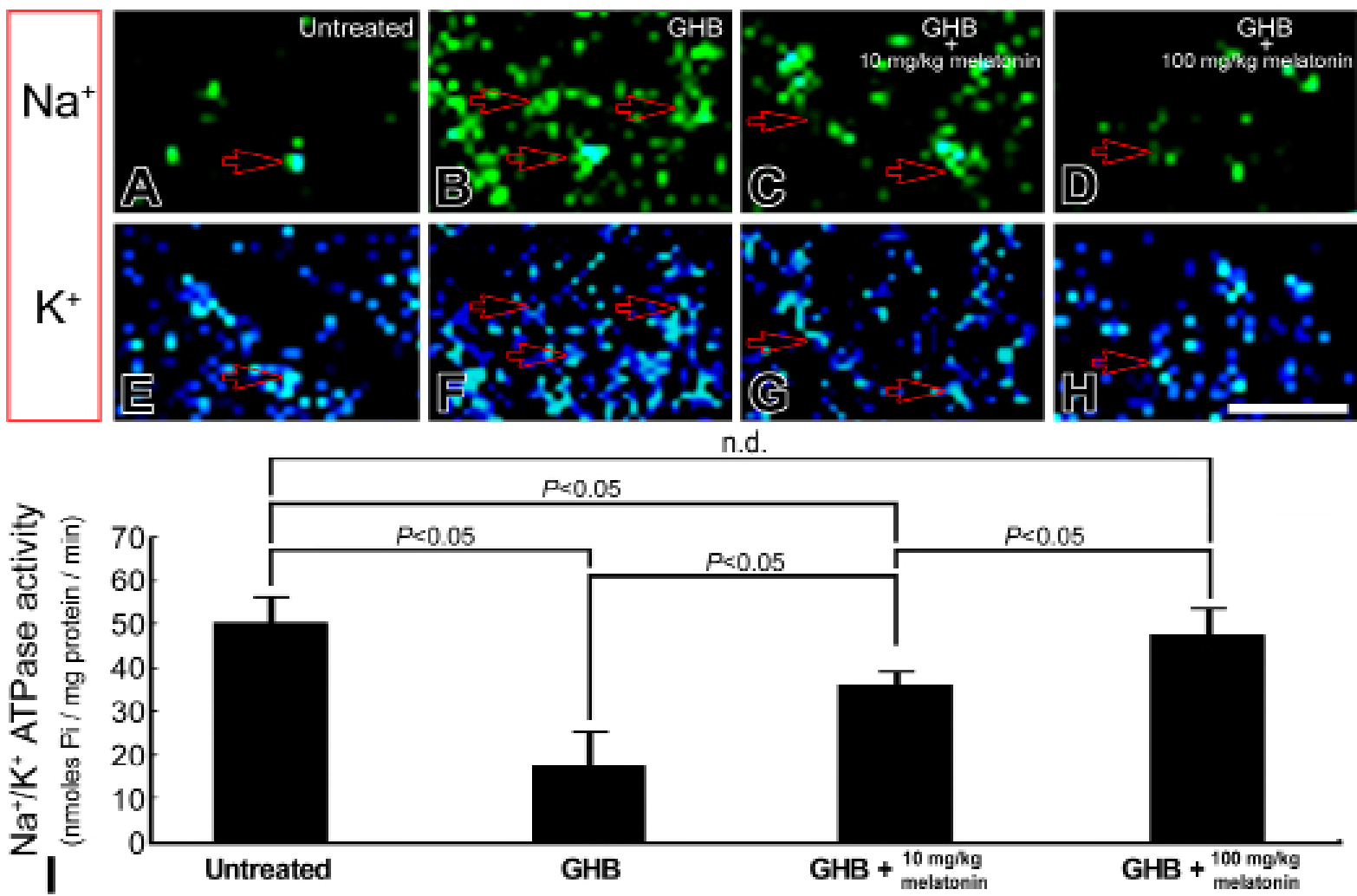

Figure 6: TOF-SIMS ionic imaging (A-H) and histogram (I) showing the intracellular $\mathrm{Na}^{+}(\mathrm{A}-\mathrm{D}), \mathrm{K}^{+}(\mathrm{E}-\mathrm{H})$, and $\mathrm{Na}^{+} / \mathrm{K}^{+}$ATPase activity (I) in the hippocampus of normal untreated (A,E), $\gamma$-hydroxybutyric acid (GHB) intoxicated (B,F), and GHB intoxication with $10 \mathrm{mg} / \mathrm{kg}(\mathrm{C}, \mathrm{G})$ and $100 \mathrm{mg} / \mathrm{kg}(\mathrm{D}, \mathrm{H})$ melatonin treated rats. Note that in normal untreated rats, mild $\mathrm{Na}^{+}$and intense $\mathrm{K}^{+}$signaling were detected in the intracellular portion [arrows in (A) and (E)] of hippocampal neurons. The relative low level of intracellular $\mathrm{Na}^{+}$corresponded well with the normal expression of $\mathrm{Na}^{+} / \mathrm{K}^{+}$ATPase activity (I). However, following GHB intoxication, excessive accumulation of intracellular $\mathrm{Na}^{+}$was observed in hippocampal neurons [arrows in (B)]. The impairment of ionic regulation after GHB was evidently expressed by disrupted $\mathrm{Na}^{+} / \mathrm{K}^{+}$ATPase activity (I). Nevertheless, in animals intoxicated by $\mathrm{GHB}$ and received different doses of melatonin, the $\mathrm{Na}^{+} / \mathrm{K}^{+}$ATPase activity was significantly recovered (I) which coincided well with the reduction of hippocampal intracellular $\mathrm{Na}^{+}$overload [arrows in (C) and (D)]. Scale bar $=100 \mu \mathrm{m}$. (A-H).

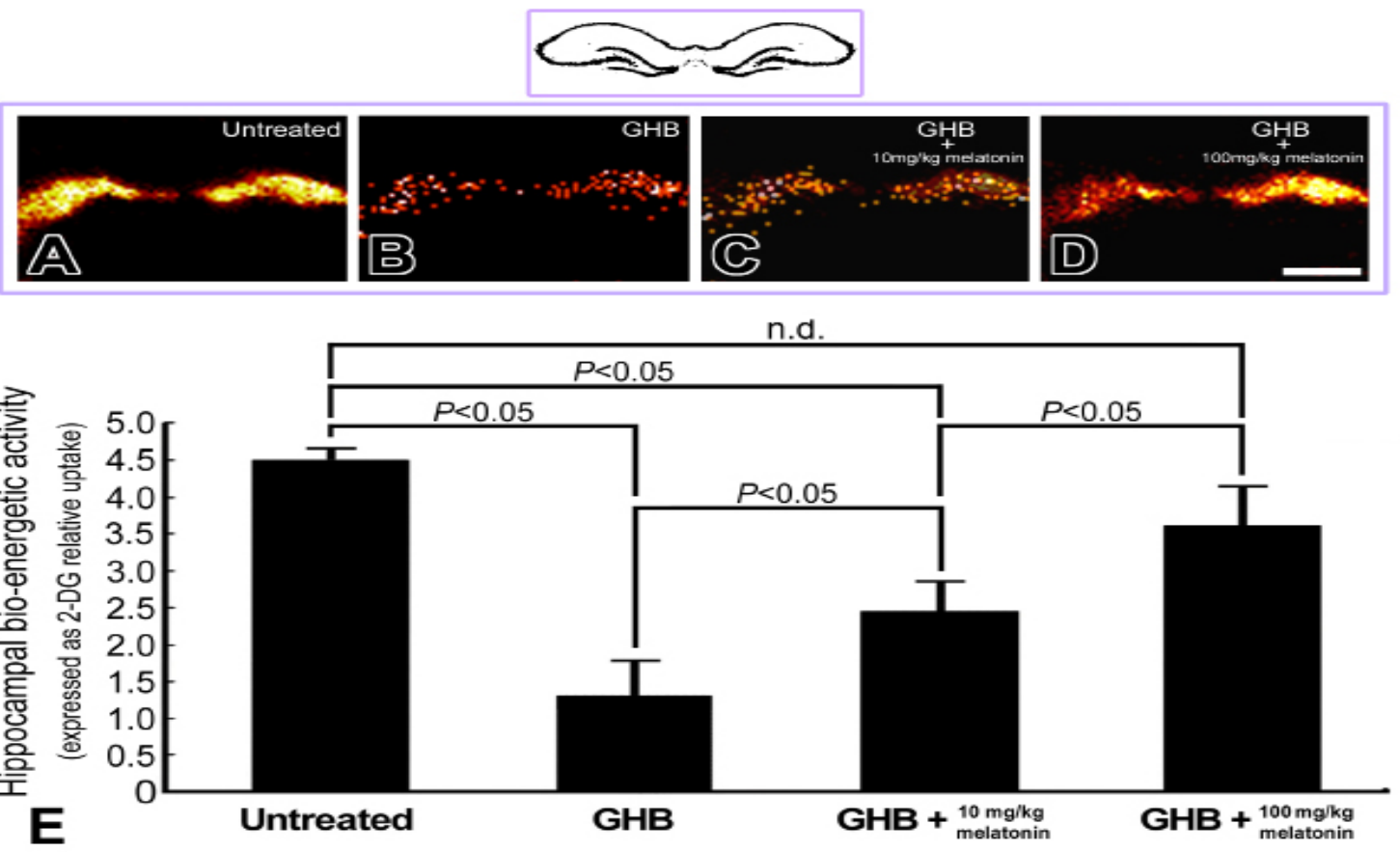

Figure 7: Colored autoradiograms (A-D) and histogram (E) showing the bio-energetic status [as demonstrated by $\left[{ }^{14} \mathrm{C}\right]-2$-deoxyglucose $(2-\mathrm{DG})$ activity] in the hippocampus of normal untreated (A), $\gamma$-hydroxybutyric acid (GHB) intoxicated (B), and GHB intoxication with $10 \mathrm{mg} / \mathrm{kg}$ (C) and 100 $\mathrm{mg} / \mathrm{kg}(\mathrm{D})$ melatonin treated rats. Note that in normal untreated rats, strong radioactive signals for 2-DG was expressed in the hippocampal regions (A). Following GHB intoxication, the signal intensity of hippocampal 2-DG was drastically decreased (B). However, in animals intoxicated by GHB and received different doses of melatonin, the hippocampal 2-DG signals was successfully returned to nearly normal levels in which the maximal recovery was detected in animals received $100 \mathrm{mg} / \mathrm{kg}$ of melatonin (D,E). Scale bar $=1200 \mu \mathrm{m}$. (A-D). 

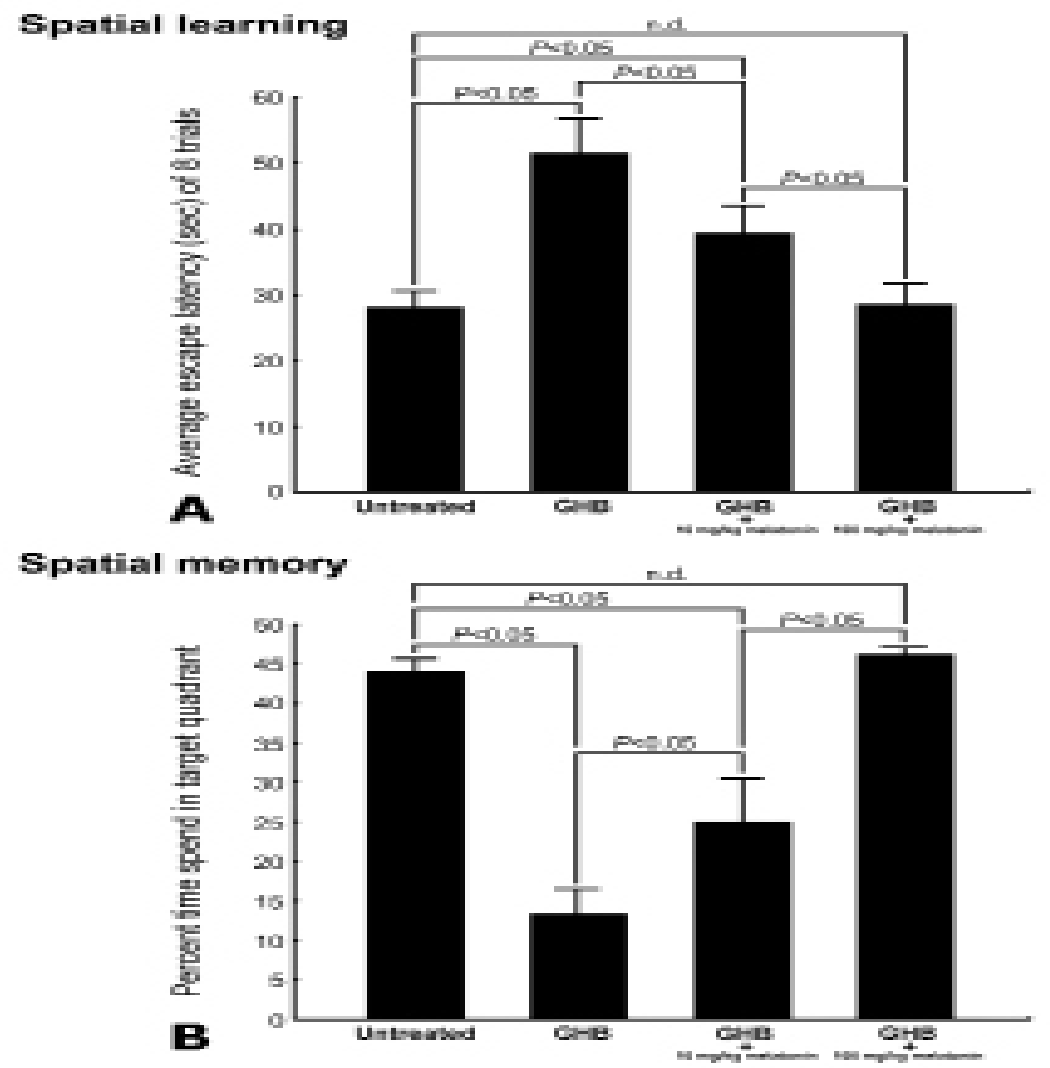

Figure 8: Histograms showing the cognitive function [as demonstrated by spatial learning (A) and spatial memory (B) in the Morris water maze test] of normal untreated, $\gamma$-hydroxybutyric acid (GHB) intoxicated, and GHB intoxicated with $10 \mathrm{mg} / \mathrm{kg}$ and $100 \mathrm{mg} / \mathrm{kg}$ melatonin treated rats. Note that there was a significant impairment of cognitive function following GHB intoxication. However, following different doses of melatonin treatment, the cognitive function was effectively improved as revealed by reducing the average escape latency (A) and extending the percent time spent in the target quadrant (B).

However, in animals subjected to chronic and excessive doses of GHB, the hippocampal $\mathrm{Ca}^{2+}$ expression was drastically decreased in both terms of spectral intensity and ionic imaging (Figure 1B,E). The decrement of hippocampal Ca ${ }^{2+}$ corresponded well with diminished NMDA receptor expression (Figure 2B,E), lower level of nNOS activity (Figure 3), and reduced p-CREB immunoreactivity (Figure 4B,E), which all demonstrated the molecular profiles of depressed $\mathrm{Ca}^{2+}$-mediated signaling. Biochemical and auto-radiographic measurements correlated well with the molecular findings in which enhanced oxidative stress (Figure 5), disrupted $\mathrm{Na}^{+} / \mathrm{K}^{+}$ATPase activity (Figure 6B,F,I), and reduced 2-DG signaling (Figure 7B,E) were all clearly detected in the hippocampus of animals subjected to GHB. The impairment of $\mathrm{Na}^{+} / \mathrm{K}^{+}$ATPase activity was clearly manifested by ionic imaging wherein unexpected high levels of $\mathrm{Na}^{+}$were accumulated in the intracellular portion of hippocampal neurons instead of pumping outward (arrows in Figure 6B). Data collected from behavioral testing paralleled to these findings in which animals bearing with impaired hippocampal bio-energetics (Figure 5,6 and 7) definitely showed poor performances in cognitive activity (Figure 8). Nevertheless, it is noteworthy that the cognitive deficits observed in behavioral testing did not result from potential motoric dysfunction induced by GHB, since GHB (at least in our dosage) did not affect the cued task performance in Morris water maze testing (i.e. no significant difference was detected in swimming speed between normal untreated rats and GHB-treated ones) (Table 1).

\begin{tabular}{|c|c|c|c|c|}
\hline & $\begin{array}{l}\text { Normal } \\
\text { Untreated }\end{array}$ & GHB & $\begin{array}{c}\text { GHB with } \\
\text { Melatonin } \\
(10 \mathrm{mg} / \mathrm{kg})\end{array}$ & $\begin{array}{c}\text { GHB with } \\
\text { Melatonin } \\
(100 \mathrm{mg} / \mathrm{kg})\end{array}$ \\
\hline \multicolumn{5}{|c|}{ Molecular elements engaged in the induction of LTP } \\
\hline $\mathrm{Ca}^{2+}$ intensity (\% above base line) & $643 \pm 54$ & $246 \pm 86^{*}$ & $427 \pm 30^{*} \dagger$ & $598 \pm 76 \dagger$ \\
\hline NMDAR1 Staining intensity & $1.62 \pm 0.12$ & $0.61 \pm 0.06$ & $1.12 \pm 0.17^{*} \dagger$ & $1.47 \pm 0.05 \dagger$ \\
\hline nNOS activity (U/mg) & $33.5 \pm 2.81$ & $14.3 \pm 4.56$ & $27.5 \pm 1.25^{*} \dagger$ & $33.4 \pm 3.06 \dagger$ \\
\hline pCREB staining intensity & $1.81 \pm 0.05$ & $0.63 \pm 0.11^{*}$ & $1.31 \pm 0.13^{*} \dagger$ & $1.67 \pm 0.09 \dagger$ \\
\hline \multicolumn{5}{|l|}{ Bio-energetics } \\
\hline Oxidative stress (nmol/g) & $100 \pm 9.53$ & $173 \pm 5.54$ & $132 \pm 6.77^{*} \dagger$ & $96 \pm 15.4 \dagger$ \\
\hline $\mathrm{Na}+/ \mathrm{K}+$ ATPase activity (nmol Pi/mg/min.) & $50 \pm 5.81$ & $17 \pm 8.37^{*}$ & $36 \pm 2.79^{*} \dagger$ & $47 \pm 6.28 \dagger$ \\
\hline 2-DG radioactivity & $4.5 \pm 0.21$ & $1.3 \pm 0.52$ & $2.5 \pm 0.44^{*} \dagger$ & $3.7 \pm 0.59 \dagger$ \\
\hline
\end{tabular}




\begin{tabular}{|c|c|c|c|c|}
\hline & $\begin{array}{c}\text { Normal } \\
\text { Untreated }\end{array}$ & GHB & $\begin{array}{l}\text { GHB with } \\
\text { Melatonin } \\
(10 \mathrm{mg} / \mathrm{kg})\end{array}$ & $\begin{array}{l}\text { GHB with } \\
\text { Melatonin } \\
(100 \mathrm{mg} / \mathrm{kg})\end{array}$ \\
\hline \multicolumn{5}{|l|}{ Cognitive expression } \\
\hline Spatial learning (sec.) & $27.7 \pm 2.2$ & $51.3 \pm 5.0^{*}$ & $39.1 \pm 4.1^{*} \dagger$ & $39.1 \pm 4.1^{*} \dagger$ \\
\hline Spatial memory (\% time) & $44 \pm 1.69$ & $13 \pm 3.30^{*}$ & $25 \pm 5.63^{*} \dagger$ & $25 \pm 5.63^{*} \dagger$ \\
\hline Cued task (cm/min.) & $25.43 \pm 1.13$ & $27.06 \pm 2.13$ & $26.47 \pm 2.24$ & $26.47 \pm 2.24$ \\
\hline
\end{tabular}

GHB: $\gamma$-hydroxybutyric acid; LTP: long term potentiation; NMDAR1: $N$-methyl-D-aspartate receptor subunit 1; nNOS: neuronal nitric oxide synthase; pCREB: phosphorylated cAMP- responsive element binding protein; 2-DG: [14C]-2-deoxyglucose. ${ }^{*}: P<0.05$ as compared to normal untreated values; $\dagger: P<0.05$ as compared to GHB values

Table 1: Numerical data summarizing the advanced effects of melatonin on protecting the hippocampal neurons and cognitive function from GHB-induced injury

On the contrary, in animals subjected to GHB and received different doses of melatonin, all the ionic, molecular, and biochemical parameters detected in hippocampal neurons were gradually returned to nearly normal levels. Ionic imaging revealed that following melatonin administration, hippocampal $\mathrm{Ca}^{2+}$ was increasingly expressed (Figure 1C,D) in which the maximal intensity was observed in animals given the dose of $100 \mathrm{mg} / \mathrm{kg}$ (Figure 1D). Similar findings were also observed in $\mathrm{Ca}^{2+}$-mediated signaling wherein hippocampal NMDA receptor (Figure 2C,D), nNOS activity (Figure 3), and p-CREB immuno-expression (Figure 4C,D) were all significantly increased in animals given different doses of melatonin. Up-regulation of these molecular elements paralleled well with the improvement of hippocampal bio-energetics in which the maximal reduction of oxidative stress (Figure 5), enhancement of $\mathrm{Na}^{+} / \mathrm{K}^{+}$ATPase activity (Figure 6C,D,G,H), and recovery of 2-DG intensity (Figure 7C,D) were clearly detected in animals received $100 \mathrm{mg} / \mathrm{kg}$ of melatonin. The beneficial effects of melatonin on preserving the cognitive function after GHB was further documented by behavioral testing in which the performance of spatial learning (Figure 8A) and spatial memory (Figure $8 \mathrm{~B}$ ) was effectively be improved in animals treated with melatonin at either 10 or $100 \mathrm{mg} / \mathrm{kg}$.

\section{Discussion}

The present study provides the first functional anatomical evidence that melatonin effectively increase hippocampal Ca ${ }^{2+}$ expression (Figure 1), enhance $\mathrm{Ca}^{2+}$-mediated molecular element activation (Figures 2, 3 and 4), decrease hippocampal oxidative stress (Figure 5), improve neuronal bio-energetics (Figures 6, 7), and ultimately contribute to the recovery of cognitive function following GHB intoxication injury (Figure 8). The beneficial effect of melatonin was dose dependent, since the most obvious changes were detected in animals receiving higher dose of melatonin (Figures 1-8). It is well known that $\mathrm{Ca}^{2+}$ is an essential element participated in the induction of LTP [16]. Dys-homeostasis of $\mathrm{Ca}^{2+}$ would depress the efficacy of LTP that consequently leads to the impairment of cognitive function [38,39]. Although the detailed mechanism of GHB-induced cognitive dysfunction is not fully understood, our present study thus suggested that reduced hippocampal $\mathrm{Ca}^{2+}$ (Figure 1) may also contribute to cognitive dysfunction since this reduction is positively correlated with the poor performances in spatial learning (Figure 8A) and spatial memory (Figure 8B). This implication was further supported by our neurochemical findings in which depressed $\mathrm{Ca}^{2+}$-mediated signaling (Figures 2 , 3 and 4), enhanced oxidative stress (Figure 5), and impaired hippocampal bio-energetics (Figures 6 and 7) were all detected in animals intoxicated by large amounts of GHB. Considering melatonin could modulate $\mathrm{Ca}^{2+}$ signaling and regulate neuroplasticity in the hippocampus [40,41], exogenous use of melatonin may therefore serve as a promising strategy to counteract or improve the GHB-induced cognitive deficiency. This is just the case that in our current study, we have clearly demonstrated that melatonin effectively preserved the activity of hippocampal $\mathrm{Ca}^{2+}$-mediated molecular machinery (Figures 1, 2, 3 and 4) and successfully rescued the cognitive function (Figure 8) in animals subjected to GHB. The beneficial effects of melatonin may exert through receptor-dependent and/or receptor-independent pathway since both MT1 and MT2 receptors of melatonin has already been identified in the hippocampal neurons [42]. To the best of our knowledge, there is no report designed to systemically examine the neuro-protective effects of melatonin on improving the cognitive function following club drug intoxication. As the present study is the first one employing multidisciplinary approaches to display the neuro-protective effects of melatonin after GHB, delivering melatonin may be of great help to prevent or reduce the cognitive dysfunction induced by GHB addiction prevailing in our society now a days.

In addition to enhance the molecular signaling in hippocampal neurons (Figures 1, 2, 3 and 4), the positive effects of melatonin on depressing the oxidative stress (Figure 5) and improving the cellular bio-energetics (Figures 6 and 7) should not be overlooked. Enhanced oxidative stress could cause lipid peroxidation that inevitably disrupts the function of $\mathrm{Na}^{+} / \mathrm{K}^{+} \mathrm{ATPase}$, which has been reported to be positively correlated with the formation of learning and memory deficiency $[43,44]$. Our current report coincided well with previous studies in which we also demonstrated a reduced hippocampal $\mathrm{Na}^{+} / \mathrm{K}^{+}$ATPase following GHB, which consequently disrupts the neuronal bio-energetics (Figures 6 and 7) and contributes to the development of cognitive deficiency (Figure 8). Although the pharmacological interaction between melatonin and GHB-induced neurotoxicity requires to be further investigated, these findings thus supports the experimental use of melatonin in improving the cognitive function since melatonin also bears powerful effects on reducing the oxidative stress (Figure 5) and preserving the bio-energetics (Figures 6 and 7) in hippocampus as well as in other brain regions $[30,32,36]$. 
Another important issue to be addressed is the dose of melatonin administrated in the current study. Many studies have indicated that melatonin exerts a beneficial effect at endogenously produced levels [45]. However, despite that physiological levels of melatonin are capable of reducing neuronal injury, the neuro-protective effects of melatonin at this level are best viewed as a decrease in oxidative stresses that generally accompanies normal aging or age-related neuro-degenerative diseases [45]. In the case of drug intoxication wherein oxidative stress is much more intense, physiological levels of melatonin may be inadequate to counteract the massive production of reactive oxygen species and protect against the oxidative damage. It has been reported that melatonin can be tolerated in large doses by humans and animals without severe adverse effects [46]. With regard to this viewpoint, pharmacological or exceptionally high levels of melatonin should be introduced to combat excessive oxidative injury, and therefore, effectively preserve the cognitive activity. Nevertheless, caution must be exercised when discussing the biological functions of melatonin on cognitive expression, since the neuro-protective effects of melatonin may directly arise from this indole's anxiolytic action that might significantly suppress the anxiogenic impact of GHB on cognitive activity [47]. Based on this suggestion, it is worthy to explore the potential influence of melatonin on anxiety-like behavior induced by GHB (e.g. by performing the open field or elevated plus maze test) as attempts to further clarify the neuro-protective mechanism(s) exerted by melatonin.

In summary, with the assistance of advanced spectrometric, ionic imaging, biochemical as well as behavioral approaches, the present study addressed for the first time that melatonin effectively preserves hippocampal bio-energetics and successfully rescues cognitive function in GHB intoxicated rats. Although the detailed mechanism(s) related to the benefits of melatonin in bioenergetic regulation is still not fully understood, decreasing the oxidative stress, increasing hippocampal $\mathrm{Ca}^{2+}$-mediated signaling, and enhancing $\mathrm{Na}^{+} / \mathrm{K}^{+}$ATPase activity may all contribute to the formation of such efficiency [28]. Considering melatonin is positive for maintaining normal cognitive function, therapeutic use of melatonin may serve as an attractive strategy for clinical use to prevent or reduce the social problems resulting from club drug addiction.

\section{Acknowledgement}

The authors are grateful to Dr. S-L Lei for her expert technical assistance. This study is supported by the research grant (104TMUTMUH-09) to Dr. H-M Chang from the Taipei Medical University, Taipei, Taiwan. The authors confirm that there are no known conflicts of interest associated with this research and there has been no significant financial support for this work that could have influenced its outcome.

\section{References}

1. Boyce SH, Padgham K, Miller LD, Stevenson J (2000) Gamma-hydroxybutyric acid (GHB): an increasing trend in drug abuse. Eur J Emerg Med 7: 177-81.

2. Wong CG1, Gibson KM, Snead OC $3^{\text {rd }}$. (2004) From the street to the brain: neurobiology of the recreational drug gamma-hydroxybutyric acid. Trends Pharmacol Sci 25: 29-34.

3. Wu LT1, Schlenger WE, Galvin DM (2006) Concurrent use of methamphetamine, MDMA, LSD, ketamine, GHB, and flunitrazepam among American youths. Drug Alcohol Depend 84: 102-13.

4. Raess BU, Tunnicliff G (2002) Abuse potential and toxicology of gamma-hydroxybutyrate. In: Gamma-hydroxybutyrate: Molecular, Functional, and Clinical Aspects, Taylor and Francis, London.

5. Hicks AR, Varner KJ (2008) Cardiovascular responses elicited by intragastric administration of BDL and GHB. J Recept Signal Transduct Res 28: 429-36.

6. Sircar R, Basak A, Sircar D (2008) Gamma-hydroxybutyric acid-induced cognitive deficits in the female adolescent rat. Ann N Y Acad Sci 1139: 386-9.

7. Pedraza C, Garcia FB, Navarro JF (2009) Neurotoxic effects induced by gamma-hydroxybutyrix acid (GHB) in male rats. Int J Neuropsychopharmacol 12: 116577.

8. van Amsterdam JG, Brunt TM, McMaster MT, Niesink RJ (2012) Possible long-term effects of gamma-hydroxybutyric acid (GHB) due to neurotoxicity and overdose. Neurosci Behav Rev 36: 1217-27.

9. Brennan R, Van Hout MC (2014) Gamma-hydroxybutyrate (GHB): a scoping review of pharmacology, toxicology, motives for use, and user groups. J Psychoactive Drugs 46: 243-51.

10. Foster TC (2007) Calcium homeostasis and modulation of synaptic plasticity in the aged brain. Aging Cell 6: 319-25.

11. Chang HM, Liao WC, Sheu JN, Chang CC, Lan CT, et al. (2012) Sleep deprivation impairs $\mathrm{Ca}^{2+}$ expression in the hippocampus: ionic imaging analysis for cognitive deficiency with TOF-SIMS. Microsc Microanal 18: 425-35.

12. Jiang W, Yu Q, Gong M, Chen L, Wen EY, et al. (2012) Vitamin A deficiency impairs postnatal cognitive function via inhibition of neuronal calcium excitability in hippocampus. J Neurochem 121: 932-43.

13. Bliss TV, Collingridge GL (1993) A synaptic model of memory: long-term potentiation in the hippocampus. Nature 361: 31-9.

14. Akhondzadeh S (1999) Hippocampal synaptic plasticity and cognition. J Clin Pharm Ther 24: 241-8.

15. Lynch MA (2004) Lon-term potentiation and memory. Physiol Rev 84: 87-136.

16. Malenka RC (1991) The role of postsynaptic calcium in the induction of long-term potentiation. Mol Neurobiol 5: 289-95.

17. Nicoll RA, Malenka RC (1999) Expression mechanisms underlying NMDA receptor-dependent long-term potentiation. Ann N Y Acad Sci 868: 515-25.

18. Hawkins RD, Son H, Arancio O (1998) Nitric oxide as a retrograde messenger during long-term potentiation in hippocampus. Prog Brain Res $118:$ 155-72. 19. Lu YF, Kandel ER, Hawkins RD (1999) Nitric oxide signaling contributes to late-phase LTP and CERB phosphorylation in the hippocampus. J Neurosci 19: 10250-61.

20. Sircar R, Basak A (2004) Adolescent gamma-hydroxybutyric acid exposure decreases cortical N-methyl-D-aspartate receptor and impairs spatial learning. Pharmacol Biochem Behav 79: 701-8. 
21. Sgaravatti AM, Sgarbi MB, Testa CG, Durigon K, Pederzolli CD, et al. (2007) Gamma-hydroxybutyric acid induces oxidative stress in cerebral cortex of young rats. Neurochem Int 50: 564-70.

22. Kemmel V, Klein C, Dembélé D, Jost B, Taleb O, et al. (2010) A single acute pharmacological dose of gamma-hydroxybutyric acid (GHB) modified multiple gene expression patterns in rat hippocampus and frontal cortex. Physiol Genomics 41: 146-60.

23. Hogan MV, El-Sherif Y, Wieraszko A (2001) The modulation of neuronal activity by melatonin: in vitro studies on mouse hippocampal slices. J Pineal Res 30: 87-96.

24. Ozcan M, Yilmaz B, Carpenter DO (2006) Effects of melatonin on synaptic transmission and long-term potentiation in two areas of mouse hippocampus. Brain Res 1111: 90-4.

25. Shibata S, Cassone VM, Moore RY (1989) Effects of melatonin on neuronal activity in the rat suprachiasmatic nucleus in vitro. Neurosci Lett 97: 140-4.

26. Gorfine T, Zisapel N (2007) Melatonin and the human hippocampus, a time dependent interplay. J Pineal Res 43: 80-6.

27. Furio AM1, Brusco LI, Cardinali DP (2007) Possible therapeutic value of melatonin in mild cognitive impairment: a retrospective study. J Pineal Res 43: 404-9. 28. Chang HM, Wu UI, Lan CT (2009) Melatonin preserves longevity protein (SIRT1) expression in the hippocampus of total sleep-deprived rats. J Pineal Res 47: 211-20.

29. Manda K, Reiter RJ (2010) Melatonin maintains adult hippocampal neurogenesis and cognitive functions after irradiation. Prog Neurobiol 90: 60-8.

30. Jangra A, Datusalia AK, Khandwe S, Sharma SS (2013) Amelioration of diabetes-induced neurobehavioral and neurochemical changes by melatonin and nicotinamide: implication of oxidative stress-PARP pathway. Pharmacol Biochem Behav 115: 43-51.

31. New DC, Tsim ST, Wong YH (2003) G protein-linked effector and second messenger systems involved in melatonin signal transduction. Neurosignals 12: 59-70.

32. Zhang L1, Zhang HQ, Liang XY, Zhang HF, Zhang T, et al. (2013) Melatonin ameliorates cognitive impairment induced by sleep deprivation in rats: role of oxidative stress, BDNF and CaMKII. Behav Brain Res 256: 72-81.

33. Chang HM, Mai FD, Chen BJ, Wu UI, Huang YL, et al. (2008) Sleep deprivation predisposes liver to oxidative stress and phospholipid damage: a quantitative molecular imaging study. J Anat 212: 295-305.

34. Sheu JN, Liao WC, Wu UI, Shyu LY, Mai FD, et al. (2013) Resveratrol suppresses calcium-mediated microglial activation and rescues hippocampal neurons of adult rats following acute bacterial meningitis. Comp Immunol Microb 36: 137-48.

35. Amaral AC, Jakovcevski M, McGaughy JA, Calderwood SK, Mokler DJ, et al. (2015) Prenatal protein malnutrition decreases KCNJ3 and 2DG activity in rat prefrontal cortex. Neuroscience 286: 79-86.

36. Chang HM, Tseng CY, Wei IH, Lue JH, Wen CY, et al. (2005) Melatonin restores the cytochrome oxidase reactivity in the nodose ganglia of acute hypoxic rats. J Pineal Res 39: 206-14.

37. Chen LY, Tiong C, Tsai CH, Liao WC, Yang SF, et al. (2015) Early-life sleep deprivation persistently depresses melatonin production and bio-energetics of the pineal gland: potential implications for the development of metabolic deficiency. Brain Struct Funct 220: 663-76.

38. Green KN, Smith IF, Laferla FM (2007) Role of calcium in the pathogenesis of Alzheimer's disease and transgenic models. Subcell Biochem 45: 507-21.

39. Takeda A, Yamada K, Tamano H, Fuke S, Kawamura M, et al. (2008) Hippocampal calcium dyshomeostasis and long-term potentiation in 2-week zinc deficiency. Neurochem Int 52: 241-6.

40. El-Sherif Y1, Tesoriero J, Hogan MV, Wieraszko A (2003) Melatonin regulates neuronal plasticity in the hippocampus. J Neurosci Res 72: 454-60.

41. de Faria Poloni J, Feltes BC, Bonatto D (2011) Melatonin as a central molecule connecting neural development and calcium signaling. Funct Integr Genomics 11: 383-8.

42. Musshoff U, Riewenherm D, Berger E, Fauteck JD, Speckmann EJ (2002) Melatonin receptors in rat hippocampus: molecular and functional investigations. Hippocampus 12: 165-73.

43. dos Reis EA, de Oliveira LS, Lamers ML, Netto CA, Wyse AT (2002) Arginine administration inhibits hippocampal Na(+),K(+)-ATPase activity and impairs retention of an inhibitory avoidance task in rats. Brain Res 951: 151-7.

44. Moseley AE, Williams MT, Schaefer TL, Bohanan CS, Neumann JC, et al. (2007) Deficiency in Na,K-ATPase alpha isoform genes alters spatial learning, motor activity, and anxiety in mice. J Neurosci 27: 616-26.

45. Reiter RJ, Tan DX, Qi W, Manchester LC, Karbownik M, et al. (2000) Pharmacology and physiology of melatonin in the reduction of oxidative stress in vivo. Biol Signals Recept 9: 160-71.

46. Reiter RJ, Tan DX, Ganano A (2014) Melatonin: exceeding expectations. Physiology (Bethesda) 29: 325-33.

47. Marseglia L, D’Angelo G, Manti S, Aversa S, Arrigo T, et al. (2015) Analgesic, anxiolytic and anaesthetic effects of melatonin: new potential uses in pediatrics. Int J Mol Sci 16: 1209-20.

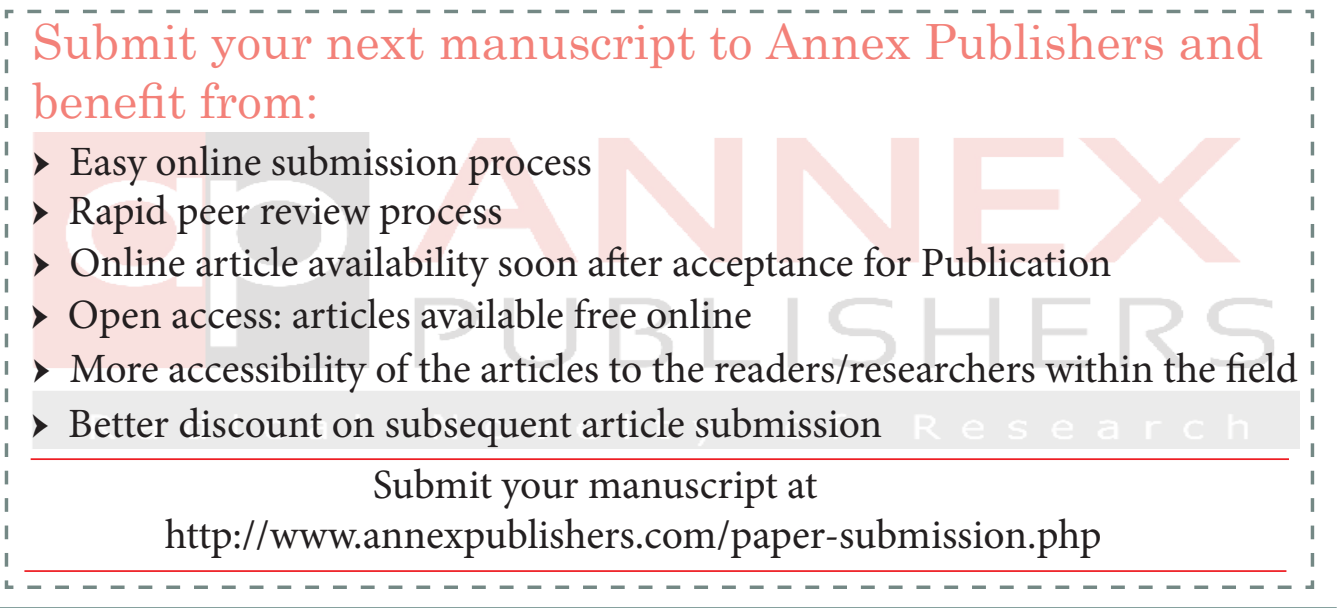

